\title{
Wave reflection from nearshore depressions
}

\author{
David R. Michalsen ${ }^{1}$, Merrick C. Haller ${ }^{2}$, Kyung Duck Suh ${ }^{3}$
}

Abstract: This study employs an existing finite-difference model based on the hyperbolic form of the Modified Mild Slope Equation (MMSE) to investigate wave reflection near bathymetric depressions such as dredged borrow pits and nearshore canyons. First, the model is tested for numerical limitations on the higher order bottom slope and curvature terms using atidealized cases of a simple depth transition and a symmetric trapezoidal trench, with comparisons of the MMSE to both the traditional Mild Slope Equation (MSE) solution and a shallow water analytic solution. It is demonstrated that the model gives accurate solutions on slopes as steep as 1:1, and that the solutions from all three models agree in the shallow water region. However, for waves in intermediate depths, predicted wave reflection from nearshore depressions is shown to differ significantly between the MMSE and MSE models. Next, geometrical data from a wide range of existing and proposed borrow pits and a submarine canyon are gathered and analyzed for whether wave reflection is an important process near realistic nearshore depressions. The geometric data show that realistic nearshore depressions lie within the tested range of the MMSE model and that borrow pits are generally not in shallow water, which means it is important to use an MMSE-type model to calculate reflection from these features. In addition, storm conditions on average lead to a 50\% increase in reflection coefficient in comparison to the mean wave conditions, due to the increase in wave period. Finally, the results also indicate borrow pit design criteria that can be used to ensure minimal reflection.

${ }^{1}$ Civ. Engr., U.S. Army Corps of Engrs., Portland District, P.O. Box 2946, Portland, OR 977208-2956. E-mail: david.r.michalsen@nwp01.usace.army.mil

${ }^{2}$ Asst. Prof., Department of Civil, Construction and Environmental Engineering, Oregon State University, Corvallis, Oregon 97331-2302. E-mail: hallerm@engr.orst.edu

${ }^{3}$ Professor, School of Civil, Urban, and Geosystem Engineering \& Engineering Research Institute, Seoul National University, Seoul 151-742, Korea; formally visiting scholar at Oregon State University. E-mail: kdsuh@snu.ac.kr 
CE Database subject headings: wave reflection, offshore borrow pits, nearshore canyon, modified mild slope equation

\section{Introduction}

Localized topographic features on the sea floor will induce scattering of surface waves if the waves of interest are long enough to "feel" the bottom feature, i.e. if the local water depth is less than about half the length of the waves. The induced scattering processes include refraction, diffraction, and reflection, and the amount of scattering is more pronounced and more difficult to model numerically as the steepness of the bottom features increases. Steep bottom features are either depressions or obstacles, and can be natural or manmade. Examples of depressions / obstacles include submarine canyons / submerged rock outcrops and dredged pits / submerged breakwaters, respectively. For features that are steep-sided in the direction of wave approach, significant energy can be reflected backwards. In addition, variations in depth in the lateral directions will induce wave divergence (from depressions) or convergence (from obstacles) through the process of refraction. When reflection and/or wave divergence is dominant, a shadow region of decreased wave energy is created leeward of the feature, and this may lead to strong longshore wave height gradients in the nearshore.

Recently, there has been an increased interest in the wave shadowing effects of borrow holes left behind after the dredging of nearshore sand deposits. This interest was initiated after early case studies (e.g. Motyka and Willis, 1974; Combe and Soileau, 1987) where crescentic patterns of localized shoreline erosion were observed in the lee of these manmade bottom features. It has now become standard practice to pre-assess the potential shoreline impact of proposed nearshore dredge sites through modeling efforts that couple some of the wave scattering effects of the borrow holes with the resulting wave-driven currents, sediment transport, and shoreline response (e.g. Byrnes et al., 2004, Demir et al., 2004, Maa et al., 2004, Work et al., 2004). 
Steep bathymetric features can also occur naturally on rocky coastlines, such as the U.S. West Coast, and they can be a dominant control on the wave propagation in the coastal zone and potentially control the shape of the shoreline. For example, the Scripps and La Jolla Canyons in southern California have long been known to strongly modify the incident nearshore wave conditions through wave refraction (e.g. Munk and Traylor, 1947; Shepard and Inman, 1950). The refractive scattering from these canyons induces longshore variations in both wave height and wave breaking, which in turn quite often lead to rip currents (for a recent analysis see Long and Özkan-Haller, 2005). Hence, the scattering can play an important role in the nearshore dynamics. Recently, Thomson et al. (2005) provided evidence of significant reflection of infragravity waves (periods between 20 and 200 s) from La Jolla Canyon. However, the importance of wave reflection at sea and swell frequencies near these canyons has not been quantified.

Steep obstacles in the form of nearshore reefs and detached breakwaters are typically strong wave reflectors and dissipaters and thus provide effective shelter from storm waves. Larson et al. (1997) and Black and Andrews (2001) showed how the sheltering effect of such obstacles can also lead to the formation of salients (i.e. shoreline accretion). This is a seemingly opposite result from the erosion that has been sometimes observed leeward of borrow holes in the field. From the existing literature it appears evident that the specific shoreline response will depend not only on the nature and amount of wave scattering from the given bathymetric feature but also on how the wave scattering translates into variations in nearshore wave breaking and wave-generated currents, which are the fundamental drivers of sediment transport and shoreline response. As pointed out by Bender and Dean (2004), additional uncertainty arises from the fact that models for shoreline change are typically based on divergences in bulk longshore sediment transport, and shoreline erosion or accretion in the lee of borrow holes is highly dependent on the poorly constrained longshore transport coefficients.

As one step towards understanding how these types of local bottom features can affect shoreline response, it is necessary to quantify the importance of the various wave scattering processes in modifying 
the nearshore wave environment. It should be noted that virtually all shoreline impact assessment studies for borrow sites neglect the processes of wave reflection and often also wave diffraction. Recently, Bender and Dean (2005) presented an analytic model that includes all of the relevant scattering processes from nearshore obstacles and that can also be coupled to a simple shoreline planform change model (Bender and Dean, 2004). In the present work, we also investigate the potential importance of wave reflection on the wave scattering from steep nearshore features; however, we utilize a more general existing wave model based on a finite difference solution that includes all the relevant scattering processes and can handle arbitrary (non-idealized) bottom topographies. It is noted that while finite difference solutions for wave propagation over steep nearshore features will introduce practical difficulties of their own (as shown later), for better or for worse, numerical solutions are still the method of choice for practical situations. Hence, it is of interest to test their ability to simulate the scattering from steep features.

In the following sections, we first compare solutions from the present model to both a previous finite-difference model and an analytic long wave solution to verify the range of validity of the model. In addition, we compare some basic parameter relationships regarding reflection coefficients and the wavenumbers of peak reflection. Subsequently, we present tabulated values of a large number of existing and proposed borrow pits in order to constrain the parameter space of the analysis to a realistic range. Finally, we assess the practical importance of wave reflection from a range of realistic (based on field observations) borrow hole and canyon geometries.

\section{Wave Modeling}

Most wave models used for practical studies are based on the mild-slope equation (MSE) first given by Berkhoff (1972). In general, the MSE is capable of simulating shoaling, refraction, diffraction, and reflection of linear water waves. However, in the numerical implementation of these models, only 
forward propagation is typically considered (see Maa et al., 2000 and Bender and Dean, 2003 for reviews). Hence, backward reflection is neglected, which suggests that the transmission of wave energy past steep bottom features is overestimated by these models.

There is an additional limitation in the accurate prediction of wave scattering by models based on the MSE arising from the (mild slope) assumption that $|\nabla h| / k h<<1$ (where $h$ is the water depth and $k$ is the wavenumber). Booij (1983) argued that accurate predictions of wave reflection using the MSE were limited to bottom slopes of less than 1:3 by showing that, for certain wave conditions, the MSE solution does not agree with the exact finite element method (FEM) solution to the Laplace equation for bottom slopes greater than 1:3. Later, Suh et al. (1997) found that for other wave conditions the MSE solution does not agree with the exact FEM solution, even for slopes less than 1:3. These errors in the MSE solution are primarily due to the bottom curvature induced by the slope discontinuity at both ends of the transitional slope. Lee et al. (1998) found the mild-slope approximation to be even more limiting when waves of a range of relative water depths $k h$ were considered. Finally, Kirby and Misra (unpublished manuscript) argued that the MSE is not the correct leading-order approximation even for a slowly varying sea bed.

A number of extensions to the MSE have been proposed in order to relax the mild-slope restriction, but it is generally accepted that the modified equation derived by Massel (1993) and Chamberlain and Porter (1995), i.e. the so-called modified mild-slope equation (MMSE), yields significantly more accurate solutions for waves over rapidly varying bathymetry when compared to the original MSE. The improved accuracy of the MMSE arises from the inclusion of higher order terms proportional to the squared bottom slope, $(\nabla h)^{2}$, and the bottom curvature, $\nabla^{2} h$. In addition to the original works, further results demonstrating the improved accuracy of the MMSE have been given by Chandrasekera and Cheung (1997), Suh et al. (1997), and Lee and Yoon (2004).

It seems clear that models based on the MMSE are better suited for simulating wave reflection from steep topographies. For practical applications, where our interest is ultimately in the shoreline 
response to the presence of localized bottom features, it is also necessary to choose a model that can handle non-idealized bathymetries. For these reasons, we have chosen the finite difference formulation of the MMSE as given by Lee et al. (1998). Since this model solves the equations in hyperbolic form, it also has the advantage of requiring shorter computational times as compared to models using the elliptical form. First, we will investigate the numerical limitations of this MMSE solution when modeling steep bathymetries. Next, we will quantify the reflection that occurs on realistic, steep bathymetric features such as borrow holes and nearshore canyons in order to determine if this is an important effect in real situations.

\section{$1 D$ model formulation}

The MMSE formulation of Lee et al. (1998) constitutes a hyperbolic system of first-order equations here given by

$\frac{\partial \eta}{\partial t}+\frac{1}{\frac{C_{g}}{C}-R_{1}(\nabla h)^{2}-R_{2} \nabla^{2} h} \nabla \cdot Q=0$

$$
\frac{\partial Q}{\partial t}+C C_{g} \nabla \eta=0
$$

where $\eta$ is the water surface elevation, $t$ is time, $C$ is the phase speed, $C_{g}$ is the group velocity, and $R_{1}$ and $R_{2}$ are terms that contain the higher-order bottom effects given as

$$
R_{1}=\frac{1}{\cosh ^{2} k h}\left(W_{1} I_{1}+W_{2} I_{2}+W_{3} I_{3}+W_{4} I_{4}+W_{5} I_{5}+W_{6}\right)
$$


$R_{2}=\frac{1}{\cosh ^{2} k h}\left(U_{1} I_{1}+U_{2} I_{2}+U_{3} I_{3}\right)$

where $W_{i}, U_{i}$, and $I_{i}$ can be found in the appendix of Suh et al. (1997). The terms $W_{i}$ and $U_{i}$ are weighting functions and the $I_{i}$ terms correspond to depth integrals of various hyperbolic functions; all of these terms are dependent on $k h$. If the $R_{1}$ and $R_{2}$ terms are neglected, Eqs. (1) and (2) reduce to the MSE model of Copeland (1985). In their numerical implementation, Lee et al. (1998) uses a conservative grid size to wavelength ratio of 60 to guarantee satisfactory spatial resolution.

The bottom slope squared and bottom curvature terms are represented using standard central differences as

$$
\begin{aligned}
& {\left[\left(\frac{d h}{d x}\right)^{2}\right]_{i}=\left(\frac{h_{i+j}-h_{i-j}}{2 j \cdot \Delta x}\right)^{2}} \\
& {\left[\frac{d^{2} h}{d x^{2}}\right]_{i}=\frac{h_{i+j}-2 h_{i}+h_{i-j}}{(j \cdot \Delta x)^{2}},}
\end{aligned}
$$

where, strictly speaking, $j$ is unity. However, a problem arises when the denominator of the second term in Eq. (1) becomes negative (i.e. $\left\{C_{g} / C-R_{l}(\nabla h)^{2}-R_{2} \nabla^{2} h\right\} \leq 0$ ), which tends to occur at sharp transitions in depth where the curvature is large. As an empirical fix, Lee et al. (1998) recommend altering the curvature and slope squared terms locally by selecting the smallest possible integer $j$ necessary to keep the denominator term in Eq. (1) positive (essentially dampening the magnitude of these terms at these specific cells). In order to maintain a continuous representation of these terms, the number of cells modified needs 
to be $2 j+1$ and centered about the problem cell. Hence, as $j$ increases so does the number of cells that are affected.

Waves are generated internally near the offshore boundary following the technique originally described by Madsen and Larsen (1987) for the model of Copeland (1985). The formulation allows backscattered waves to pass freely through the source region. Sponge layers are placed at each boundary to prevent reflections. For further details of the numerical implementation of the model, the reader is referred to Lee et al. (1998) and Suh et al. (2001).

\section{Numerical Tests}

Lee et al. (1998) demonstrated the variation of the higher order terms $\left(R_{1}\right.$ and $\left.R_{2}\right)$ from shallow to deep water. Both terms are small in deep water, however they both are nonzero in the intermediate depth region $(\pi / 10<k h<\pi)$. In shallow water $(k h<\pi / 10)$, the slope squared term $\left(R_{l}\right)$ is nonzero but $R_{2}$ is very small. As shown by those authors, most of the differences between the MSE and MMSE solutions are the result of $R_{2}$. Thus, the differences between the two solutions are expected to be the most pronounced near steep-sided (large curvature) features and in intermediate depths.

In the original work of Lee et al. (1998), the model was validated against both a finite element model solution for the problem of wave reflection from a single, steep slope, and against experimental data from Davies and Heathershaw (1984) for the problem of Bragg scattering from a rippled bed. We also note that in both of those problems the incident waves were in intermediate relative water depths. Hence, the model is well suited for application to the problem of wave reflection from realistic bottom features in intermediate depths. We will, however, investigate the limitations of the present numerical solution for areas of high curvature, i.e. what impact does the requirement that the denominator term in Eq. (1) remain positive have on the calculation of reflection coefficients? 


\section{Reflection from a single slope}

In order to determine the maximum allowable curvature the model can handle we return to the problem of wave reflection from a linear sloping transition problem first analyzed by Booij (1983) with the MSE. For this case, waves with a period of $2 \mathrm{~s}$ are generated in an initially quiescent fluid and a uniform depth of $0.6 \mathrm{~m}$. The waves propagate over a transition slope into a second uniform depth region of $0.2 \mathrm{~m}$ and, after steady-state conditions are reached, $K_{r}$ is calculated using the spatial variations of the wave envelope (see Dean and Dalrymple, 2000) in the uniform depth region between one and two wavelengths offshore of the slope.

For this model domain and wave condition we note that when $\Delta x=0.1 \mathrm{~m}$, if $\nabla h>2$, the denominator in the second term of Eq. (1) becomes negative. Hence, for steeper slopes, it is necessary to locally increase the value of the integer $j$ in Eqs. (5) and (6) near the corner (slope break) points at the top of the slope where the curvature is strongly positive, which dampens the magnitude of the curvature and slope squared terms. This is in effect a local bathymetric smoothing. In addition, changing the value of $\Delta x$ or $k h$ may also affect the sign of the denominator term. For example, fixing the bathymetry but increasing the wave period (decreasing $k h$ ) decreases the denominator term, which may require increasing $j$. The effect on the calculated reflection coefficient of locally increasing $j$ is demonstrated in Table 1.

For a transition slope of $\nabla h=2$, the denominator term is non-negative and the reflection coefficient can be calculated using the standard value of $j=1$. As previously demonstrated by Lee et al. (1998), the value of $K_{r}$ calculated for these conditions by the MMSE model is 0.230 , compared to a value of 0.167 for the MSE model (the MSE solution is obtained here by specifying $R_{l}=R_{2}=0$ ). Table 1 shows the impact on the calculated $K_{r}$ when $j$ is locally modified. Increasing $j$ from 1 to 2 causes the largest absolute reduction in the maximum curvature and slope squared terms; but significant changes in the reflection coefficient do not arise until $j=7$, corresponding to modification of 15 of the 801 cells (or $1.9 \%$ ) in the domain, leading to reduction of $10 \%$ in $K_{r}$. These results indicate that, as long as the higherorder bottom terms remain of the appropriate order of magnitude, their impact is felt and the MMSE 
solution remains the most accurate. However, if $j$ is increased so much as to reduce these terms by more than an order of magnitude, then the reflection calculated by the MMSE tends to reduce to the MSE value. Nonetheless, this result gives us some confidence that minor adjustments in the $j$ value (locally, in areas of high curvature) will not adversely affect the calculation of the reflection coefficients.

\section{Reflection from a trench with sloping walls}

As a final test of the limit on curvature imposed by the numerical scheme, we calculate wave reflection from two trapezoidal trenches and also compare to the analytical long wave solution of Liu and Lin (2005; hereafter referred to as LL), which is a closed-form version of the slope method of Bender and Dean (2003b). The trench dimensions of the test cases are sketched in Figure 1 and are the same as was given by Bender and Dean (see their Figure 6). The depths $h_{l}$ (outside) and $h_{2}$ (inside) remain the same (2 $\mathrm{m}$ and $4 \mathrm{~m}$, respectively) for both trenches while the two trench widths, $a_{1}$ (top) and $a_{2}$ (bottom), are different between the two trenches. Hence, each trench has a different wall slope $(\nabla h=0.2$ and 1$)$ but the mean trench width, $\bar{a}=\left(a_{1}+a_{2}\right) / 2$, is the same for both. For these bathymetries, local modifications to the higher order terms via Eqs. (5) and (6) are required only for wall slope $\nabla h=1$. Here, the value $j=2$ is applied at the slope breaks on both sides of the top of the trench (not the bottom) when $k_{l} h_{1}>0.62$, resulting in a modification of 10 cells in the domain.

Figures 2 and 3 compare the dependence of $K_{r}$ on the relative water depth $k_{l} h_{l}$ outside the trench for the MMSE, MSE, and LL solutions using side slopes $\nabla h=0.2$ and 1, respectively. We show the results of the LL solution for all water depths; though recognizing that it is valid for long waves only. We discuss further the applicability of the long wave solution outside the shallow water region in the following section. Here, the results from both slopes show that for incident long waves (i.e. $k_{1} h_{l}<\pi / 10$ ) all three solutions agree well. The fact that the MMSE and MSE solutions agree in this region is expected; as pointed out by Lee et al. (1998), the curvature term explains most of the differences between the MSE 
and MMSE and the curvature term decreases in overall importance as $k h \rightarrow 0$. However, the agreement between the finite difference solutions and the analytic solution for slopes up to $\nabla h=1$ and a relative pit depth $h_{2} / h_{1}=2.0$ provides further verification for the present MMSE solution.

Finally, the figures also show significant differences between the MSE and MMSE in an intermediate range of relative depths $\left(\pi / 10<k_{l} h_{l}<1.5\right)$. The MSE model generally predicts a different location for the $K_{r}$ maxima and under predicts their magnitude, as compared to the MMSE in this range of $k_{l} h_{l}$. For example, at the third peak in Figure $3\left(k_{l} h_{l}=0.66\right)$ the MSE solution estimates $K_{r}=0.135$ whereas the MMSE estimates $K_{r}=0.250$. These results indicate that, while an MSE solution would be sufficient for calculating reflection in the shallow water regime for realistic sidewall slopes, there are significant differences between the two solutions in the intermediate depth range.

\section{Some parameterization aspects}

For design applications it would be of interest to develop a simple parameterization(s) for characterizing the amount of reflection to be expected for a given borrow pit design in order to insure the design does not exacerbate the scattering effects of the pit and potentially induce unintended nearshore circulation and shoreline response. However, this does not appear to be a simple task for realistic trenches.

Since, as previously described, wave reflection from trenches is an oscillatory function of relative water depth $\left(k_{1} h_{1}\right.$ or $\left.k_{2} h_{2}\right)$, one relevant design criterion would be to avoid pit dimensions that lead to reflection maxima that coincide with the expected dominant incident wave periods. As a starting point, we consider some existing analytical expressions that are based on the assumption of shallow water wave conditions both inside and outside of a trench. For example, the expression given in LL for trapezoidal trenches reduces to that given by Mei (1989) for the case of trenches with vertical walls. Mei (1989) showed that $K_{r}$ maxima occur at wavelengths with a fractional relationship to the dimensional trench width $(\bar{a})$ in the direction of wave propagation as given by: 


$$
\alpha_{2}=\frac{1}{2}\left(n+\frac{1}{2}\right) ; \quad n=0,1 \ldots \infty
$$

where $\alpha_{2}$ represents a non-dimensional trench width equal to $\bar{a} / \lambda_{2}$ and $\lambda_{2}$ is the dimensional wavelength of waves in the trench. From this simplified relation we can see that as trench width increases the locations of reflective maxima shift to longer wavelengths $\left(\lambda_{2} \propto \bar{a}\right)$ and the separation between reflective maxima in $k h$ (or wave period) space decreases. Hence, for larger trench widths there exists more potential for reflective conditions to occur within a given range of relative water depths or a given range of incident wave periods.

For trenches with sloping walls, however, the choice of a representative trench width is somewhat ambiguous. So, in Figure 8 we compare the location of the predicted reflective maxima $\left(\alpha_{2}\right)$ from trapezoidal trenches using the MMSE model and the LL model. The trenches considered here have a constant mean width $\left(\bar{a}=\left(a_{1}+a_{2}\right) / 2\right)$ and a range of relative trench depths $\left(1<h_{2} / h_{1}<2.5\right)$ and two different wall slopes ( $\nabla h=0.1$ and 1 ); all of these values fall within the range of realistic borrow pits (see Table 3). Interestingly, the two models show very good agreement even though the MMSE model does not assume shallow water. This indicates that the wavenumbers within the trench of the waves at the reflective maxima are only dependent on the trench geometry, regardless of the relative water depth in the trench. This is, in fact, consistent with the parameterization of Mei (1989), which effectively states that the wavelength (in the trench) of the peak reflected waves is solely determined by $\bar{a}$. The vertical trench solution would appear as horizontal lines at $0.25,0.75 \ldots$ etc in Figure 8 . As the trench slopes are reduced, the locations of reflective maxima diverge from the relation given by Eq. (7). The reason for this divergence is likely that, for trenches with sloping walls, the characteristic width is likely a weighted average of the top and bottom widths more heavily weighted toward the top width, since the waves will "feel" it more. For small relative trench depths the choice of a representative width is not ambiguous, 
hence the wall slope is immaterial to the prediction of $\alpha_{2}$. It may be possible to define an $\bar{a}$ such that the sloping trench solutions would collapse back to the vertical trench solution. However, we were unable to find such a definition. Finally, we note that in order to be consistent the corresponding reflective wavenumbers outside of the trench will be different between the MMSE and the LL models, since the LL model would use the shallow water approximation to calculate $\lambda_{1}$ from $\lambda_{2}$.

Though the reflective trench wavenumbers agree, the magnitudes of the reflective peaks differ significantly between the MMSE and LL models. Figure $9 \mathrm{a}$ and b show the magnitude of $K_{r}$ maxima for the trench geometries used in Figure 8. Here, the two solutions diverge when the relative water depth in the trench enters the intermediate range, and the differences between the models increases as the wall slope increases.

\section{Reflections from realistic steep features}

The previous results indicate there can be significant differences between the MSE, MMSE, and long wave models when used to predict wave reflection for waves of arbitrary $k h$. However, it remains to be seen whether reflection is a significant process for realistic nearshore depressions. Thus, we use the MMSE model to calculate maximum expected reflection coefficients (based on a range of wave conditions) for an extensive set of existing borrow pits, proposed borrow pit designs, and a nearshore canyon. Borrow site data has been estimated from available documentation (e.g. Motyka and Willis, 1974; Price et al., 1978; Kojima et al., 1986; Combe and Soileau, 1987; Van Dolah et al., 1998; Maa and Hobbs, 1998; Dean et al., 1999; Fernandez, 1999; Demir et al., 2004; Work et al., 2004; Walstra et al., 2003; Byrnes et al., 2004; Kelley et al., 2004). For the nearshore La Jolla Canyon, detailed bathymetric surveys were collected prior to the Nearshore Canyon Experiment (see Elgar, 2002), which took place near La Jolla, CA in the fall of 2003. Bathymetry and wave data for this experiment are available via the Coastal Data Information Program (CDIP, Scripps Institution of Oceanography) website. 


\section{Borrow pits}

Tables 2 and 3 summarize the dimensional and dimensionless parameters for both existing borrow pits and those that have been proposed but not implemented. The sites are separated into three size categories (small, moderate, and large) based on their longshore length, $b$. This is done simply to help look for trends in the data. In practice, the longshore length is also generally correlated with the volume of dredged material.

For the calculation of the reflection coefficient from these various pit geometries we take a conservative approach in that we calculate an upper bound, $\left(K_{r}\right)_{\max }$, to the amount of reflection that is likely to occur based on observed wave conditions at each site. We expect that reflection is primarily a function of the relative water depth of the incident waves $k_{l} h_{l}$, the cross-shore dimension of the pit $\bar{a}$, the relative pit depth $h_{2} / h_{1}$, and the sidewall slope. It is generally known that wave reflection increases with bottom slope, and this has been shown to apply to the case of a nearshore trench (Bender and Dean, 2003b). In practice, the maximum bed slope is limited by the angle of initial yield or, more typically, the angle of repose of the existing sediments. Allen (1970) lists a range of angles for sediment in water for various grain sizes of natural sands. The angle of initial yield ranges from $\Phi_{\mathrm{i}}=45^{\circ}$ to $53^{\circ}$ and the angle of repose $\Phi_{\mathrm{r}}=31^{\circ}$ to $37^{\circ}$. It is expected that these values represent an upper bound on realistic wall slopes for borrow pits; since it is not possible to determine the actual wall slopes from the available data, a value of $45^{\circ}(\nabla h=1)$ is used for the geometries in these calculations. As was the case in the idealized trenches considered previously, local modification $(j=2)$ of Eqs. (5) and (6) is required for the borrow pit simulations when $k_{l} h_{1}>0.62$.

In order to choose representative wave conditions for each site, five years of data are utilized from the Wave Information Study (WIS) of the U.S. Army Corps of Engineers starting from the year the particular borrow pit data were published (or earlier for the most recent publications). Table 2 contains 
the wave parameters for average wave conditions $\left(H=H_{\text {mean }}\right)$ based on the maximum monthly-mean wave height with corresponding mean peak wave period $T_{p}$. It is recognized that, in this linear analysis, reflection is primarily dependent on the wave period not the wave height; however, one might argue that if the typical wave conditions are small then even large reflection coefficients will have a minimal impact on the nearshore dynamics, so we also list the wave heights for context. Finally, since the reflection coefficient is an oscillatory function of the relative water depth as shown in Figures 2 and $3, K_{r}$ is sensitive to the wave period chosen for the calculation. Therefore, to allow for some variability in incident periods the largest reflection coefficient, $\left(K_{r}\right)_{\max }$, within $\pm 0.5 \mathrm{~s}$ of $T_{p}$ for each site is employed.

Table 3 lists the associated geometric pit parameters and maximum reflection coefficients under storm conditions for each site. Wave reflection from borrow pits during storms may be of particular interest, since wave heights are larger and wave periods generally longer, which means that the scattering effects of the pits are enhanced during these high energy conditions. Representative storm conditions are calculated using the mean of the largest $1 \%$ of wave heights $\left(H_{1 / 100}\right)$ over the record length and the mean of the corresponding $T_{p}$ for these wave heights.

We also note that in the calculation of the reflection coefficients we have taken what we believe to be a conservative approach in regards to wave obliquity. We expect that calculating the wave reflection under the assumption of normal wave incidence will lead to the maximum expected wave reflection and that modestly oblique wave angles will lead to a slight reduction in reflection coefficients. This is supported by the results of McDougal et al. (1996) and Lee et al. (2002) who found reflection to be only weakly dependent on wave direction for vertical sloping pits. However, Kirby and Dalrymple (1983) demonstrate that, at high obliquity, wave reflection can increase dramatically.

In this regard, we have tabulated an estimated angle of wave incidence, $\Gamma$, near the pits in Tables 2 and 3 by assuming the longitudinal axis of each pit is oriented parallel to the local shoreline/nearshore contours. The tabulated data indicate that the mean angle of incidence (all sites) for the average wave conditions is $26^{\circ}$ and reduces to $16^{\circ}$ for storm wave conditions. This is in accordance with the decrease 
in relative water depths during storm conditions. For completeness, we have used the analytic solution (plane wave) from Kirby and Dalrymple (1983) to estimate the potential change in reflection coefficient due to wave obliquity for pits of realistic dimensions. These calculations are given in Table 4 and indicate that for $h_{2} / h_{1} \leq 2.5$ and $\Gamma \leq 30^{\circ}$, reflection is largest when waves approach normally incident. In addition, increases in wave reflection for realistic pits do not occur until $\Gamma \geq 45^{\circ}$, which is a rare happenstance according to the field data, although it may be more likely for the case of nearshore canyons.

The data listed in Tables 2 and 3 indicate several other things as well. First, the borrow pits are generally not in shallow water, i.e. $k_{1} h_{1}, k_{2} h_{2}>\pi / 10$, which means it is important to use an MMSE-type model to characterize the reflection from these features. Second, storm conditions lead to a general increase in reflection of about $50 \%$ in comparison to the mean wave conditions with the $\left(K_{r}\right)_{\max }$, averaged over all the pits increasing from 0.10 to 0.15 . This is due to the wave periods associated with storm conditions being longer than those of the mean conditions, which changes the relative water depth of the incident waves. As expected, there is a correlation $\left(r^{2}=0.69\right.$ for storm conditions) between the amount of reflection and the relative water depth of the waves, with reflection increasing as a pit approaches shallow water conditions. There is also an even higher correlation $\left(r^{2}=0.92\right)$ between the relative pit depths $\left(h_{2} / h_{1}\right)$ and the reflection coefficient.

The overall highest reflection coefficients, $\left(K_{r}\right)_{\max } \geq 0.23$, are trenches representing Gaskin Banks, SC; Hunting Island, SC, Grand Isle, LA; Joiner Banks, SC, and the deeper trench proposed at Corson Inlet, NJ. It is of interest that the Grand Isle, LA site is predicted to be particularly reflective $\left(K_{r}=0.23\right)$ during storm conditions. Borrow pits were dredged at this site for a beach nourishment project in 1983 and the formation of erosional hot spots on the nourished beach were documented by Combe and Soileau (1987). Gravens and Rosati (1994) found that wave refraction and diffraction induced by the pits influenced the subsequent shoreline response; however, the present results suggest that wave reflection may have also played a significant role in the observed erosion. 
Finally, the results in Tables 2 and 3 also demonstrate that pits located well outside of the shallow water regime coupled with small relative pit depths, $h_{2} / h_{1} \leq 1.2$, ensure minimal reflection. However, many times dredging operations may not be able to meet these standards because this often translates to larger dredge footprints (for a given volume) and dredging at greater distances offshore where sediment characteristics are less optimal.

\section{La Jolla Canyon}

The coastal bathymetry near Scripps and La Jolla Canyons is shown in Figure 4. Wave information spanning the years 1999-2005 at this site is readily obtained from the offshore buoy CDIP Station 095 (Point La Jolla, 32.848 $\mathrm{N}-117.353^{\circ} \mathrm{W}$ ) that is located approximately 5 miles west of La Jolla Canyon outside of the area covered in Figure 4. Figure 5 shows the joint distribution of the mean direction and peak spectral period observed at this station and it is clear that incident waves approach La Jolla Canyon at a range of directions $\pm 30^{\circ}$ from normal to the canyon axis. These directions are nearly parallel to the Scripps Canyon; hence, refraction processes there are likely the most important. Therefore, wave reflection is only investigated for La Jolla Canyon.

Using the bathymetric data three parallel transects are generated along the largest depth gradient (i.e. along $D_{p}=241^{\circ}$ ) or approximately perpendicular to the trench axis as shown in Figure 6. Maximum wall slopes, $(\nabla h)_{\max }$, for these transects are fairly steep lying between 1.3 and 1.5 as listed in Table 5 . Using the three transects taken from the bathymetric data we simulate the canyon as a two-dimensional asymmetric trench in our model calculations. Local modifications to the bottom curvature/slope squared terms are required only for transect 3 . The value of $j=3$ is used at 3 different locations on the profile, which translates to 21 total grid points ( $0.2 \%$ of the domain). Figure 7 shows the calculated $K_{r}$ as a function of $k_{l} h_{l}$ for waves normally incident to Transect 1 for both the MSE and MMSE solutions. As in the previous trench cases, $K_{r}$ shows an oscillating variation with relative water depth and the largest 
differences between the MMSE and MSE occur in the intermediate depth range $\left(0.5<k_{l} h_{l}<1.5\right)$. As shown in Figure 5, the dominant swell waves at this site are near $T_{p}=13-17 \mathrm{~s}$, which corresponds to $k_{l} h_{l}$ $=0.845-1.20$ in Figure 7 . The maximum reflection coefficients from this range of periods are listed Table 4 and vary from 0.13 to 0.17 for transects $1-3$. These peak values indicate that reflection of incident swell waves is of modest importance at this site, even though the canyon is very deep with fairly steep walls. It appears likely that wave reflection is much reduced by the fact that even these long swell waves are in large relative water depths outside the canyon. Within the canyon, only waves far into the infragravity range can be considered to be in the shallow water regime.

\section{Conclusions}

The finite difference formulation of the MMSE as given by Lee et al. (1998) was used to investigate the importance of wave reflection from realistic bathymetric depressions, such as borrow pits used for beach nourishment projects and a submarine canyon. A finite difference model of this type was chosen for its improved abilities to simulate wave reflection from steep-sided bathymetric features when compared to traditional models based on the MSE of Copeland (1985). The capabilities of the present MMSE solution were previously verified for the cases of waves in arbitrary relative water depths propagating over a single transition slope and Bragg scattering from a rippled bed. Here, we further tested the model for limits on maximum allowable curvature and verified it against an analytic solution for long waves over a fairly deep and steep-sided trench.

During the testing phase the solutions from the MSE, MMSE, and LL model were shown to agree in the shallow water region. However, for waves in intermediate depths, predicted wave reflection coefficients from nearshore depressions are shown to differ significantly between the three models. An interesting further result is that, for a given borrow pit, the MMSE and LL model both predict that the location of reflective peaks in wavenumber space is only dependent on the cross-shore length scale of the 
pit, which is consistent with the analytic result of Mei (1989). However, the magnitudes of the reflection coefficients in intermediate depths differ between the MMSE and LL models are significantly different as the wall slope approaches 1:1.

An extensive set of representative borrow pit geometries from existing sites and proposed designs was collected and these real-world geometries are shown to lie within the tested ranges of the model (intermediate relative water depths, relative pit depths $\leq 2.5$, sidewall slopes $\leq 1$ ). Under the assumption that for realistic nearshore depressions wave reflection is not critically dependent on wave direction, reflection coefficients for these borrow pits along with that for a nearshore canyon were calculated by treating the bottom features as infinite trenches. The numerical results indicate that wave reflection from these features tends to increase under storm conditions because of the decrease in the relative water depth of the incident waves and there is a high correlation $\left(r^{2}=0.92\right)$ between the relative pit depth and the maximum expected reflection coefficient.. Hence, wave reflection may approach 0.40 under the right conditions and the necessary steps should be made to ensure the effects are taken into consideration at the design stage. This may be especially true if the design involves modeling processes resulting from wave scattering from the nearshore depression, such as the induced circulation, sediment transport, and shoreline response. We note that a preliminary model study suggested that significant reflective shadowing from a nearshore depression could, under certain conditions, lead to rip currents (Michalsen, 2004). Finally, the La Jolla Canyon appears to be only a modest reflector of sea and swell waves of mild obliquity to the canyon axis, which likely has a limited contribution to nearshore wave driven circulation in that area.

\section{Acknowledgements}

Funding for this work was partially provided by Oregon Sea Grant under Grant number NA16RG1039. 


\section{Notation}

The following symbols are used in this paper:

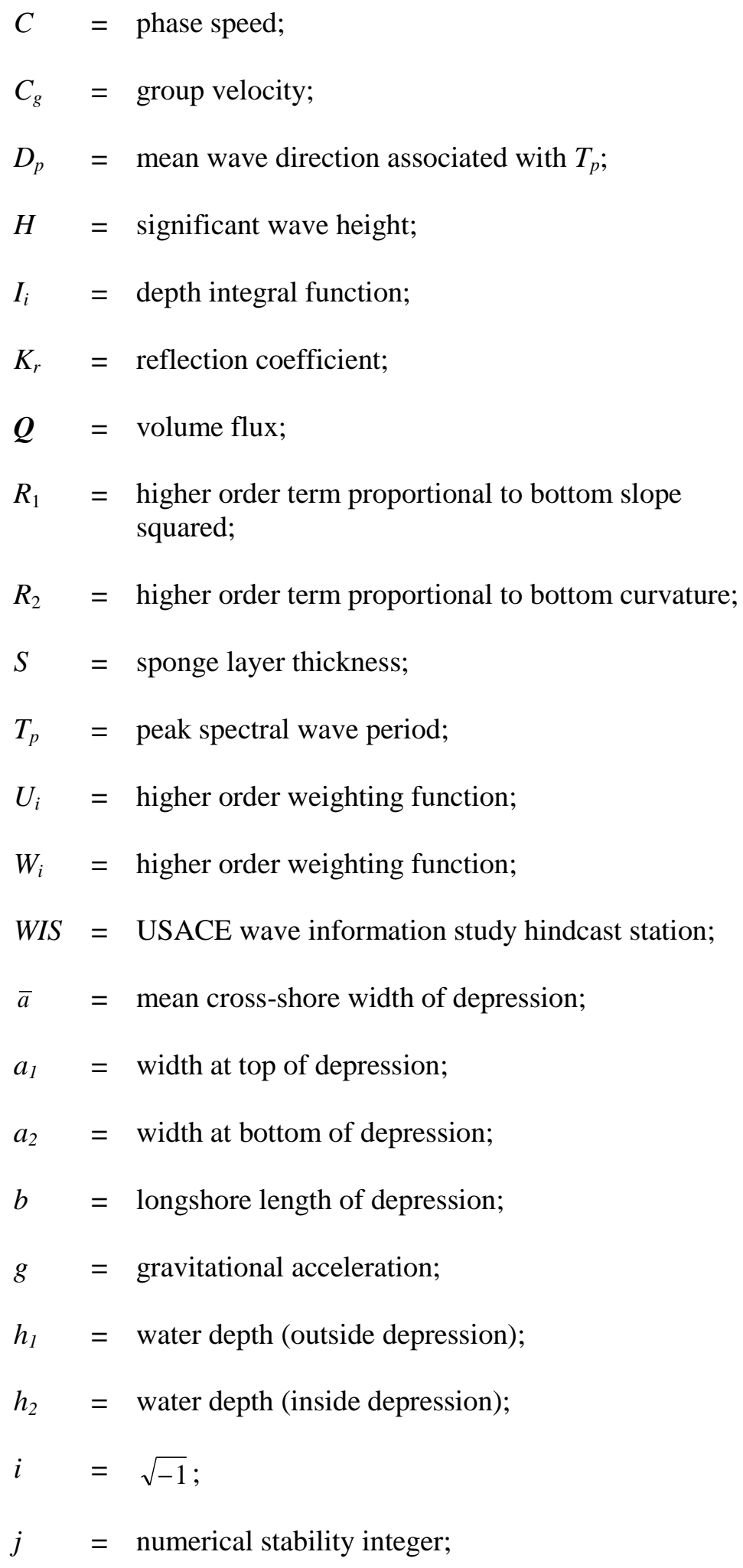




$$
\begin{array}{ll}
k_{1} & =\text { wavenumber (outside depression); } \\
k_{2} & =\text { wavenumber (inside depression); } \\
r & =\text { correlation coefficient; } \\
t & =\text { time; } \\
x & =\text { cross-shore distance; } \\
x_{p i t} & =\text { distance offshore; } \\
\beta & =\text { Shoreline orientation (from true north); } \\
\Delta x & =\text { grid spacing; } \\
\nabla & =\text { gradient operator; } \\
\Gamma & =\text { angle of incidence relative to shore normal; } \\
\Phi_{\mathrm{i}} & =\text { angle of initial yield; } \\
\Phi_{\mathrm{r}} & =\text { angle of repose; } \\
\eta & =\text { water surface elevation; } \\
\lambda_{1} & =\text { wavelength (outside depression); } \\
\lambda_{2} & =\text { wavelength (inside depression); } \\
\tilde{\phi} & =\text { velocity potential; and } \\
\omega & =\text { angular frequency. } \\
&
\end{array}
$$

\section{References}

Allen, J.R.L. (1970). "The avalanching of granular solids on dune and similar slopes." J. Geology, 78, 326-351.

Bender, C.J., and Dean, R.G. (2003a). "Wave field modification by bathymetric anomalies and resulting shoreline changes: a review with recent results." Coastal Eng., 49, 125-153.

Bender, C.J., and Dean, R.G. (2003b). "Wave transformation by two-dimensional bathymetric anomalies with sloped transitions." Coastal Eng., 50, 61-84. 
Bender, C.J., and Dean, R.G. (2004). "Potential shoreline changes induced by three-dimensional bathymetric anomalies with gradual transitions in depth." Coastal Eng., 51, 1143-1161.

Bender, C.J., and Dean, R.G. (2005). "Wave transformation by axisymmetric three-dimensional bathymetric anomalies with gradual transitions in depth." Coastal Eng., 52, 331-351.

Berkhoff, J.C.W. (1972). “Computation of combined refraction-diffraction." Proc. 13th Int. Conf. on Coastal Eng., ASCE, 471-490.

Black, K.P. and Andrews, C.J. (2001). "Sandy shoreline response to offshore obstacles part2: Discussion of formative mechanisms." J. Coastal Res., 29, 94-101.

Booij, N. (1983). "A note on the accuracy of the mild slope equation.” Coastal Eng., 7, 191-203.

Byrnes, M.R., Hammer, R.M., Thibaut, T.D., and Snyder, D.B. (2004a). "Physical and biological effects of sand mining offshore Alabama, U.S.A.” J. Coastal Res., 20(1), 6-24.

Byrnes, M.R., Hammer, R.M., Thibaut, T.D., and Snyder, D.B. (2004b). "Effects of sand mining on physical processes and biological communities offshore New Jersey, U.S.A.” J. Coastal Res., 20(1), $25-43$.

Chamberlain, P.G., and Porter, D. (1995). “The modified mild-slope equation.” J. Fluid Mech., 291, 393407.

Chandrasekera, C.N., and Cheung, K.F. (1997). "Extended linear refraction-diffraction model." $J$. Waterw., Port, Coastal, Ocean Eng., 123, 280-286.

Combe, A.J., and Soileau, C.W. (1987). "Behavior of man-made beach and dune: Grand Isle, Louisiana." Proc. Coastal Sediments 87, ASCE, New York, 1232-1242.

Copeland, G.J.M. (1985). “A practical alternative to the "mild-slope” wave equation.” Coastal Eng., 9, 125-149.

Davies, A.G., and Heathershaw, A.D. (1984). "Surface-wave propagation over sinusoidally varying topography." J. Fluid Mech., 144, 419-443. 
Dean, R.G., Liotta, R., and Simon, G. (1999). “Erosional hot spots.” UFL/COEL-99/021. Department of Coastal and Oceanographic Engineering, University of Florida.

Dean, R.G. and Dalrymple, R.A. (2000). Water wave mechanics for engineers and scientists, World Scientific, Singapore.

Demir, H., Otay, E.N., Work, P.A., and Börekçi, O.S. (2004). "Impacts of dredging on shoreline change.” J. Waterw., Port, Coastal, Ocean Eng., 130(4), 170-178.

Elgar, S. (2002). "The Nearshore Canyon Experiment." Eos Trans. AGU, 83(47), Fall Meet. Suppl., Abstract OS62E-01.

Fernandez, G.J. (1999). "Erosional hot spots at Delray Beach, Florida: mechanisms and probable causes.” Masters Thesis. Department of Civil and Coastal Engineering, University of Florida.

Gravens, M.B. and Rosati, J.D. (1994). "Numerical study of breakwaters at Grand Isle, Lousiana." Misc. Paper CERC-94-16. U.S. Army Corps of Engineers, Vicksburg, MS.

Kelley, S.W., Ramsey, J.S., and Byrnes, M.R. (2004). "Evaluating shoreline response to offshore sand mining for beach nourishment." J. Coastal Res., 20(1), 89-100.

Kirby, J.T., and Misra S.K. (1998). "A note on the modified mild-slope equation." Center for Applied. Coastal Res.

Kojima, H., Ijima, T., and Nakamuta, T. (1986). "Impact of offshore dredging on beaches along the Genkai Sea, Japan.” Proc. 20th Int. Conf. on Coastal Eng., Taipai, II, ASCE, New York, 1281-1295.

Larson, M., Hanson, H., and Kraus, N.C. (1997). "Analytical solutions of one-line model for shoreline change near coastal structures.” J. Waterw., Port, Coastal, and Ocean Eng., 123(4), 180-191.

Lee, C., Park, W.S., Cho, Y.-S. and Suh, K.D. (1998). "Hyperbolic mild slope equations extended to account for rapidly varying topography." Coastal Eng., 34, 243-257.

Lee, H.S., Williams, A.N., Lee, B.H., and Oh, J. (2002). "Diffraction of multidirectional random waves by multiple rectangular submarine pits.” Ocean Eng., 30, 85-106. 
Lee, C., and Yoon, S.B. (2004). "Effect of higher-order bottom variation terms on the refraction of water waves in the extended mild-slope equations.” Ocean Eng., 31, 865-882.

Liu, H.-W., and Lin, P.-Z. (2005). "Discussion of 'Wave transformation by two-dimensional bathymetric anomalies with sloped transitions' [Coast. Eng. 50 (2003) 61-84].” Coast. Eng., 52, 197-200.

Long, J. W., and Özkan-Haller. H.T. (2005). "Offshore controls on nearshore rip currents”, J. Geophys. Res., 110, C12007, doi:10.1029/2005JC003018.

Maa, J.P.-Y., and Hobbs, C.H. III. (1998). Physical impacts of waves on adjacent coasts resulting from dredging at Sandbridge Shoal, Virginia. J. Coastal Res., 14 (2), 525-536.

Maa, J.P.-Y., Hsu, T.-W., Tsai, C.H., Juang, W.J. (2000). “Comparison of wave refraction and diffraction models.” J. Coastal Res., 16 (4), 1073-1082.

Maa, J.P.-Y., Hobbs, C.H. III., Kim, S.C., and Wei, E. (2004). "Potential impacts of sand mining offshore of Maryland and Delaware: Part 1-Impacts on physical oceanographic processes.” $J$. Coastal Res., 20(1), 44-60.

Madsen, P.A., and Larsen, J. (1987). “An efficient finite-difference approach to the mild-slope equation." Coastal Eng., 11, 329-351.

Massel, S.R. (1993). "Extended refraction-diffraction equation for surface waves.” Coastal Eng., 19, 97126.

McDougal, W.G., Williams, A.N., and Furukawa, K. (1996). "Multiple-pit breakwaters." J. Waterw., Port, Coastal, and Ocean Eng., 122(1), 27-33.

Mei, C.C. (1989). The Applied Dynamics of Ocean Surface Waves, World Scientific, Singapore.

Michalsen, D.R. (2004). “An investigation of wave field transformation and shoreline morphology near steep bathymetric features." Masters Thesis. Department of Civil, Construction and Environmental Engineering, Oregon State University.

Motyka, J.M., and Willis, D.H. (1974). “The effect of refraction over dredged holes.” Proc. 14th Int. Conf. on Coastal Eng., Copenhagen, ASCE, New York, 615-625. 
Munk, W.H., and Traylor, M.A. (1947). "Refraction of ocean waves: A process linking underwater topography to beach erosion." J. Geol., LV(1), 1-26.

Price, W.A., Motyka, J.M. and Jaffrey, L.J. (1978). “The effect of offshore dredging on coastlines.” Proc., 16th Int. Conf. on Coastal Eng., Hamburg, ASCE, New York, 1347-1358.

Shepard, F.P., and Inman, D.L. (1950). "Nearshore circulation.” Coast. Eng., 50-59.

Suh, K.D., Lee, C., and Park, W.S., (1997). "Time-dependent equations for wave propagation on rapidly varying topography." Coastal Eng., 32, 91-117.

Suh, K.D., Lee, C., Park, Y., and Lee, T.H. (2001). "Experimental verification of two-dimensional modified mild slope equation model." Coastal Eng., 44, 1-12.

Thompson, J., Elgar, S., and Herbers, T.H.C. (2005). "Reflection and tunneling of ocean waves observed at a submarine canyon." Geophys. Res. Lett., 32, L10602, doi:10.1029/2005GL022834.

Van Dolah, R.F., Digre, B.J., Gayes, P.T., Donovan-Ealy, P. and Dowd, M.W., (1998). “An Evaluation of Physical Recovery Rates in Sand Borrow Sites Used for Beach Nourishment Projects in South Carolina." Final Report Submitted to: The South Carolina Task Force on Offshore Resources and the Mineral Management Service, Office of International Activities and Marine Minerals. 76pp plus Appendices.

Walstra, D.J.R., Rijn, L.C. van, Boers, M., and Roelvink, J.A. (2003). “Offshore sand pits: verfication and application of hydrodynamic and morphodynamic models." Proc. Coastal Sediments '03 . Clearwater Beach, USA: East Meets West Productions, Corpus Christi (TX).

Work, P.A., Fehrenbacher, F., and Voulgaris, G. (2004). "Nearshore impacts of dredging for beach nourishment." J. Waterw., Port, Coastal, and Ocean Eng., 130(6), 303-311. 
Table 1. Impact of increasing $j$ on $K_{r}(\nabla h=2, \Delta x=0.1 \mathrm{~m})$

\begin{tabular}{cccccc}
\hline & $\% \bmod ^{a}$ & $(\nabla h)^{2}$ & $\left(\nabla^{2} h\right)$ & $\begin{array}{c}K_{r} \\
(M M S E)^{\mathrm{b}}\end{array}$ & $\begin{array}{c}K_{r} \\
(M S E)^{\mathrm{b}}\end{array}$ \\
\hline$j=1$ & 0.4 & 4.00 & 20.0 & 0.230 & 0.167 \\
$j=2$ & 0.6 & 1.00 & 10.0 & 0.231 & - \\
$j=3$ & 0.9 & 0.444 & 4.44 & 0.230 & - \\
$j=4$ & 1.1 & 0.25 & 2.50 & 0.226 & - \\
$j=7$ & 1.9 & $8.16 \times 10^{-2}$ & $8.16 \times 10^{-1}$ & 0.206 & - \\
$j=10$ & 2.6 & $4.00 \times 10^{-2}$ & $4.00 \times 10^{-1}$ & 0.186 & - \\
$j=40$ & 10.1 & $2.50 \times 10^{-3}$ & $2.50 \times 10^{-2}$ & 0.168 & - \\
$j=80$ & 20.1 & $6.25 \times 10^{-4}$ & $6.25 \times 10^{-3}$ & 0.168 & - \\
\hline
\end{tabular}

${ }^{a}$ The percentage of grid points in the domain with modified slope and curvature terms (Equations 5 and 6 )

${ }^{\mathrm{b}} \mathrm{K}_{\mathrm{r}}=0.221$ in FEM solution for $\nabla h=2$ (Suh et al. 1997) 
Table 2. MMSE results for trench representing an offshore borrow site during average wave conditions (i.e. $H=H_{\text {mean }}$ )

\begin{tabular}{|c|c|c|c|c|c|c|c|c|c|c|c|c|c|c|c|c|c|c|c|c|}
\hline \multirow[b]{2}{*}{ Small $(b \leq 1 \mathrm{~km})$} & \multicolumn{6}{|c|}{ Dimensional pit characteristics } & \multicolumn{8}{|c|}{ Dimensionless pit parameters } & \multicolumn{6}{|c|}{ Average wave conditions } \\
\hline & $\begin{array}{c}\boldsymbol{b}\left(10^{2}\right) \\
(\mathrm{m})\end{array}$ & $\begin{array}{c}\bar{a}\left(10^{2}\right) \\
(\mathrm{m})\end{array}$ & $\begin{array}{l}\boldsymbol{h}_{\boldsymbol{1}} \\
(\mathrm{m})\end{array}$ & $\begin{array}{c}\boldsymbol{h}_{2} \\
(\mathrm{~m})\end{array}$ & $\begin{array}{c}\text { Vol. }\left(10^{6}\right) \\
\left(\mathrm{m}^{\wedge} 3\right)\end{array}$ & $\begin{array}{c}\boldsymbol{x}_{\text {pit }} \\
(\mathrm{km})\end{array}$ & $\left(\boldsymbol{K}_{r}\right)_{\max }^{\mathbf{b}}$ & $k_{1} h_{1}$ & $k_{2} h_{2}$ & $h_{2} / h_{1}$ & $\bar{a} / h_{l}$ & $\bar{a} / \lambda_{1}$ & $b / \lambda_{1}$ & $x_{p i t} / \lambda_{1}$ & WIS & $\begin{array}{c}\boldsymbol{H} \\
(\mathrm{m})\end{array}$ & $\begin{array}{l}T_{p} \\
(\mathrm{~s})\end{array}$ & $\begin{array}{c}\boldsymbol{D}_{p} \\
\text { (deg) }\end{array}$ & $\begin{array}{c}\boldsymbol{\beta} \\
\text { (deg) }\end{array}$ & $\begin{array}{c}\boldsymbol{\Gamma} \\
(\mathrm{deg})\end{array}$ \\
\hline Seabrook Island, SC & 6 & 2 & 3 & 4.6 & 0.1 & 0.1 & 0.17 & 0.722 & 0.934 & 1.5 & 66.7 & 7.7 & 15 & 3.8 & 348 & 1.2 & 5.2 & 148 & 87 & 29 \\
\hline Edisto Island, SC & 4 & 2 & 3 & 6.4 & 0.1 & 1 & 0.28 & 0.614 & 0.961 & 2.1 & 66.7 & 6.5 & 6.1 & 32.6 & 350 & 1.3 & 6 & 140 & 45 & -5 \\
\hline Great Yarmouth, G.B. & 8.8 & 3.1 & 7.9 & 9.9 & 0.5 & 1.2 & 0.05 & 1.427 & 1.703 & 1.2 & 38.6 & 8.8 & 20.2 & 34.5 & - & 0.5 & 5 & - & 5 & 10 \\
\hline Hunting Island, SC & 6 & 3 & 3.7 & 8 & 0.6 & 2.1 & 0.24 & 0.781 & 1.286 & 2.2 & 81.1 & 10.1 & 9.3 & 70.5 & 352 & 1.3 & 5.4 & 147 & 22 & -35 \\
\hline Gaskin Banks, SC & 6 & 12 & 3.1 & 6.1 & 1.4 & 3.3 & 0.26 & 0.662 & 0.994 & 2 & 387.1 & 40.8 & 10.4 & 112.2 & 368 & 1.2 & 5.7 & 102 & 50 & 38 \\
\hline \multicolumn{21}{|c|}{ Moderate $(1<b<3 \mathrm{~km})$} \\
\hline \multirow{2}{*}{ Genkai Sea, Japan ${ }^{\text {a }}$} & 10 & \multirow{2}{*}{10} & 13 & 16 & \multirow{2}{*}{$>0.8$} & 0.5 & 0.04 & 2.151 & 2.605 & 1.2 & 76.9 & 26.3 & 21.4 & 13.2 & \multirow[b]{2}{*}{ - } & \multirow{2}{*}{1} & \multirow[t]{2}{*}{5} & \multirow{2}{*}{315} & \multirow{2}{*}{225} & \multirow{2}{*}{$\mathbf{0}$} \\
\hline & 30 & & 20 & 25 & & 1.5 & $\mathbf{0}$ & 3.231 & 4.028 & 1.3 & 50 & 25.7 & 61.7 & 38.6 & & & & & & \\
\hline Grand Isle, LA & 13.7 & 4.6 & 4.6 & 7.7 & 2.1 & 0.8 & 0.16 & 1.035 & 1.489 & 1.7 & 100 & 16.5 & 49.1 & 28.6 & 130 & 1.2 & 4.8 & 149 & 55 & -4 \\
\hline Delray Beach, FL & 27.4 & 3 & 16 & 19 & 3.0 & 0.8 & 0.01 & 2.419 & 3.072 & 1.2 & 18.8 & 7.2 & 65.9 & 19.2 & 462 & 1.3 & 5.2 & 68 & 6 & 28 \\
\hline Joiner Banks, SC & 14 & 5 & 2.4 & 5.5 & 1 & 2.4 & 0.31 & 0.622 & 1.022 & 2.3 & 208.3 & 20.6 & 57.7 & 99 & 366 & 1.2 & 5.3 & 144 & 40 & -14 \\
\hline Sandbridge Shoal, VA & 15 & 5 & 10 & 12 & 1.5 & 3 & 0.04 & 1.399 & 1.61 & 1.2 & 50 & 11.1 & 33.4 & 66.8 & 197 & 1.2 & 5.7 & 104 & 345 & -29 \\
\hline No. Sea, Hoek van Holland & 13 & 5 & 24 & 34 & 6.5 & 10 & $\mathbf{0}$ & 3.867 & 5.473 & 1.4 & 20.8 & 12.8 & 33.3 & 256.4 & - & 0.5 & 5 & 340 & 225 & -25 \\
\hline \multirow[t]{2}{*}{ Manasquan Inlet, $\mathrm{NJ}^{\mathrm{a}}$} & 10 & 2.5 & \multirow{2}{*}{10} & \multirow{2}{*}{13} & 2.1 & 5.8 & 0.06 & \multirow{2}{*}{1.364} & \multirow{2}{*}{1.670} & \multirow{2}{*}{1.3} & 25 & 5.4 & 21.7 & 125.9 & \multirow{2}{*}{139} & \multirow{2}{*}{1.5} & \multirow{2}{*}{5.8} & \multirow{2}{*}{161} & \multirow{2}{*}{12} & \multirow{2}{*}{-59} \\
\hline & 30 & 13 & & & 8.8 & 12.5 & 0.06 & & & & 130 & 28.2 & 65.1 & 271.4 & & & & & & \\
\hline Oregon Inlet, $\mathrm{NC}^{\mathrm{a}}$ & 10 & 5 & 10 & 13 & 1.4 & 6 & 0.07 & 1211 & 1466 & 13 & 50 & 9.6 & 19.3 & 115.6 & 223 & 15 & 63 & 110 & 337 & 52 \\
\hline & 25 & 10 & 10 & 10 & 7.2 & 12.5 & 0.07 & 1.211 & 1.400 & 1.5 & 100 & 19.3 & 48.2 & 240.9 & 225 & 1.5 & 0.5 & 119 & 351 & -52 \\
\hline Large $(b \geq 3 \mathrm{~km})$ & & & & & & & & & & & & & & & & & & & & \\
\hline Anna Maria Key, FL & 30.5 & 3.4 & 6 & 9.1 & 1.6 & 0.5 & 0.12 & 1.140 & 1.543 & 1.5 & 56.7 & 10.3 & 92.2 & 15.1 & 273 & 1.3 & 5.1 & 257 & 150 & -17 \\
\hline Kilyos, Turkey & 33 & 13 & 13 & 17 & 16 & 1 & $\mathbf{0}$ & 2.007 & 2.561 & 1.3 & 100 & 31.9 & 81.1 & 24.6 & - & 1.0 & 5.2 & - & 270 & 45 \\
\hline Hutchinson Island, FL & 38 & 17 & 8 & 12.5 & 24 & 5 & 0.12 & 1.137 & 1.575 & 1.6 & 212.5 & 38.5 & 86 & 1131 & & & & & 330 & \\
\hline & 50 & 17 & 10 & 14.5 & 24 & 5 & 0.09 & 1.330 & 1.775 & 1.5 & 170 & 36 & 80.4 & 113.1 & 454 & 1.5 & 5.9 & 72 & 330 & -12 \\
\hline Corson Inlet, NJ & 33 & 11 & 10 & 12 & 7.2 & 7 & 0.04 & 1.364 & 1.566 & 1.2 & 110 & 23.9 & 71.6 & 152 & 141 & 1.5 & 5.8 & 164 & 30 & -44 \\
\hline & & & & 19 & 32.6 & & 0.12 & & 2.317 & 1.9 & & & & & & & & & & \\
\hline
\end{tabular}

${ }^{a}$ multiple examined borrow sites-only the lower and upper bounds of the each dimension are expressed.

${ }^{\mathrm{b}}$ corresponds to closest peak within $\pm 0.5 \mathrm{sec}$ of the corresponding peak wave period $T_{p}$. 
Table 3. Refer to Table 2; storm wave conditions $\left(H=H_{1 / 100}\right)$

\begin{tabular}{|c|c|c|c|c|c|c|c|c|c|c|c|c|c|c|}
\hline \multirow[b]{2}{*}{ Small $(b \leq 1 \mathrm{~km})$} & \multicolumn{8}{|c|}{ Dimensionless pit parameters } & \multicolumn{6}{|c|}{ Storm wave conditions } \\
\hline & $\left(\boldsymbol{K}_{r}\right)_{\max }^{\mathrm{b}}$ & $k_{1} h_{1}$ & $k_{2} h_{2}$ & $h_{2} / h_{1}$ & $\bar{a} / h_{l}$ & $\bar{a} / \lambda_{I}$ & $b / \lambda_{1}$ & $x_{p i i} / \lambda_{1}$ & WIS & $\begin{array}{c}\boldsymbol{H} \\
(\mathrm{m})\end{array}$ & $\begin{array}{l}\boldsymbol{T}_{\boldsymbol{p}} \\
(\mathrm{s})\end{array}$ & $\begin{array}{c}\boldsymbol{D}_{\boldsymbol{p}} \\
(\mathrm{deg})\end{array}$ & $\begin{array}{c}\boldsymbol{\beta} \\
(\mathrm{deg}) \\
\end{array}$ & $\begin{array}{c}\boldsymbol{\Gamma} \\
(\mathrm{deg})\end{array}$ \\
\hline Seabrook Island, SC & 0.19 & 0.362 & 0.454 & 1.5 & 66.7 & 3.8 & 7.5 & 1.9 & 348 & 3.6 & 9.8 & 124 & 87 & 53 \\
\hline Edisto Island, SC & 0.17 & 0.271 & 0.401 & 2.1 & 66.7 & 2.9 & 2.7 & 14.4 & 350 & 4.7 & 13 & 134 & 45 & 1 \\
\hline Great Yarmouth, G.B. & 0.09 & 0.769 & 0.881 & 1.2 & 38.6 & 4.7 & 10.9 & 18.6 & - & 2 & 8 & - & 5 & 10 \\
\hline Hunting Island, SC & 0.33 & 0.388 & 0.587 & 2.2 & 81.1 & 5 & 4.6 & 35 & 352 & 3.5 & 10.2 & 129 & 22 & -17 \\
\hline Gaskin Banks, SC & 0.30 & 0.394 & 0.566 & 2 & 387.1 & 24.3 & 6.2 & 66.8 & 368 & 3.2 & 9.2 & 111 & 50 & 29 \\
\hline \multicolumn{15}{|c|}{ Moderate $(1<b<3 \mathrm{~km})$} \\
\hline \multirow{2}{*}{ Genkai Sea, Japan ${ }^{a}$} & 0.06 & 1.047 & 1.205 & 1.2 & 76.9 & 12.8 & 10.4 & 6.4 & \multirow{2}{*}{ - } & \multirow{2}{*}{2.5} & \multirow{2}{*}{8} & \multirow{2}{*}{315} & \multirow{2}{*}{225} & \multirow{2}{*}{$\mathbf{0}$} \\
\hline & 0.05 & 1.364 & 1.47 & 1.3 & 50 & 10.9 & 26.1 & 16.3 & & & & & & \\
\hline Grand Isle, LA & 0.23 & 0.444 & 0.587 & 1.7 & 100 & 7.1 & 21 & 12.3 & 130 & 3.8 & 10 & 153 & 55 & -8 \\
\hline Delray Beach, FL & 0.06 & 0.934 & 1.043 & 1.2 & 18.8 & 2.8 & 25.5 & 7.4 & 462 & 4 & 9.7 & 66 & 6 & 30 \\
\hline Joiner Banks, SC & 0.37 & 0.337 & 0.522 & 2.3 & 208.3 & 11.2 & 31.3 & 53.6 & 366 & 3.2 & 9.4 & 125 & 40 & 5 \\
\hline Sandbridge Shoal, VA & 0.07 & 0.623 & 0.691 & 1.2 & 50 & 5 & 14.9 & 29.7 & 197 & 3.9 & 10.8 & 96 & 345 & -21 \\
\hline No. Sea, Hoek van Holland & 0.10 & 1.171 & 1.509 & 1.4 & 20.8 & 3.9 & 10.1 & 77.7 & - & 5 & 10 & 340 & 225 & 25 \\
\hline \multirow[t]{2}{*}{ Manasquan Inlet, $\mathrm{NJ}^{\mathrm{a}}$} & 0.11 & \multirow{2}{*}{0.617} & \multirow{2}{*}{0.716} & \multirow{2}{*}{1.3} & 25 & 2.5 & 9.8 & 57 & \multirow{2}{*}{139} & \multirow{2}{*}{4.3} & \multirow{2}{*}{10.9} & \multirow{2}{*}{117} & \multirow{2}{*}{12} & \multirow{2}{*}{-15} \\
\hline & 0.11 & & & & 130 & 12.8 & 29.5 & 122.7 & & & & & & \\
\hline \multirow[t]{2}{*}{ Oregon Inlet, $\mathrm{NC}^{\mathrm{a}}$} & 0.11 & \multirow{2}{*}{0.605} & \multirow{2}{*}{0.701} & \multirow{2}{*}{1.3} & 50 & 4.8 & 9.6 & 57.8 & \multirow{2}{*}{223} & \multirow{2}{*}{5.5} & \multirow{2}{*}{11.1} & \multirow{2}{*}{89} & 337 & -22 \\
\hline & 0.11 & & & & 100 & 9.6 & 24.1 & 120.4 & & & & & & \\
\hline Large $(b \geq 3 \mathrm{~km})$ & & & & & & & & & & & & & & \\
\hline Anna Maria Key, FL & 0.18 & 0.529 & 0.667 & 1.5 & 56.7 & 4.8 & 42.8 & 7 & 273 & 3.8 & 9.7 & 262 & 150 & -22 \\
\hline Kilyos, Turkey & 0.07 & 1.256 & 1.533 & 1.3 & 100 & 20 & 50.7 & 15.4 & - & 3 & 7 & N/A & 270 & 15 \\
\hline Hutchinson Island, FL & 0.19 & 0.562 & 0.723 & 1.6 & 212.5 & 19 & 42.5 & 50 & 154 & 42 & 106 & 50 & 230 & 1 \\
\hline & 0.14 & 0.637 & 0.789 & 1.5 & 170 & 17.2 & 38.5 & S.9. & 434 & 4.3 & 10.0 & 39 & 530 & 1 \\
\hline Corson Inlet, NJ & 0.08 & 0503 & 0.657 & 1.2 & 110 & 104 & 1 & 661 & 41 & 42 & 12 & 20. & 0 & 0 \\
\hline & 0.25 & נינ.0. & 0.860 & 1.9 & 110 & 10.4 & 51.1 & 00.1 & 141 & 4.3 & 11.0 & 120 & 50 & 0 \\
\hline
\end{tabular}


Table 4. Influence of wave incidence angle and relative trench depth on reflection coefficient (first peak in $k h$ space) using plane wave solution from Kirby \& Dalrymple (1983), $\bar{a} / h_{1}=100$, superscripts denote angle of wave incidence.

\begin{tabular}{cccc}
\hline $\boldsymbol{h}_{2} / \boldsymbol{h}_{\boldsymbol{1}}$ & $\boldsymbol{K}_{\boldsymbol{r}}^{\mathbf{0}}$ & $\boldsymbol{K}_{\boldsymbol{r}}^{\mathbf{1 6}}$ & $\boldsymbol{K}_{\boldsymbol{r}}^{\mathbf{2 6}}$ \\
\hline 1.5 & 0.20 & 0.18 & 0.14 \\
2.5 & 0.43 & 0.37 & 0.24 \\
\hline
\end{tabular}


Table 5. Maximum reflection coefficient for La Jolla Canyon transects $(\Delta x=2 \mathrm{~m})$

\begin{tabular}{cccccccc}
\hline Transect & $j$ & $\% \bmod$ & $(\nabla h)_{\max }$ & $k_{1} h_{1}$ & $k_{2} h_{2}$ & $\begin{array}{c}K_{r} \\
(M S E)\end{array}$ & $\begin{array}{c}K_{r} \\
(M M S E)^{a}\end{array}$ \\
\hline 1 & 1 & $0 \%$ & 1.30 & 0.892 & 2.956 & 0.07 & 0.13 \\
2 & 1 & $0 \%$ & 1.53 & 0.874 & 2.591 & 0.14 & 0.17 \\
3 & 3 & $0.2 \%$ & 1.45 & 0.984 & 2.890 & 0.08 & 0.14 \\
\hline
\end{tabular}

${ }^{a}$ Maxima in $K_{r}$ for wave periods $T=13-17 \mathrm{sec}$ 


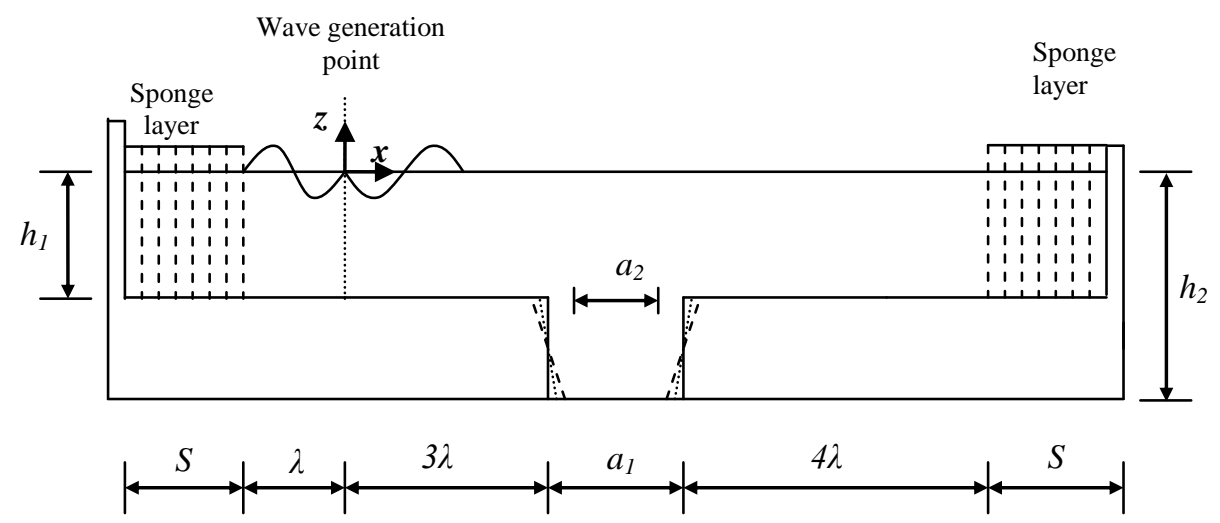

Fig. 1 


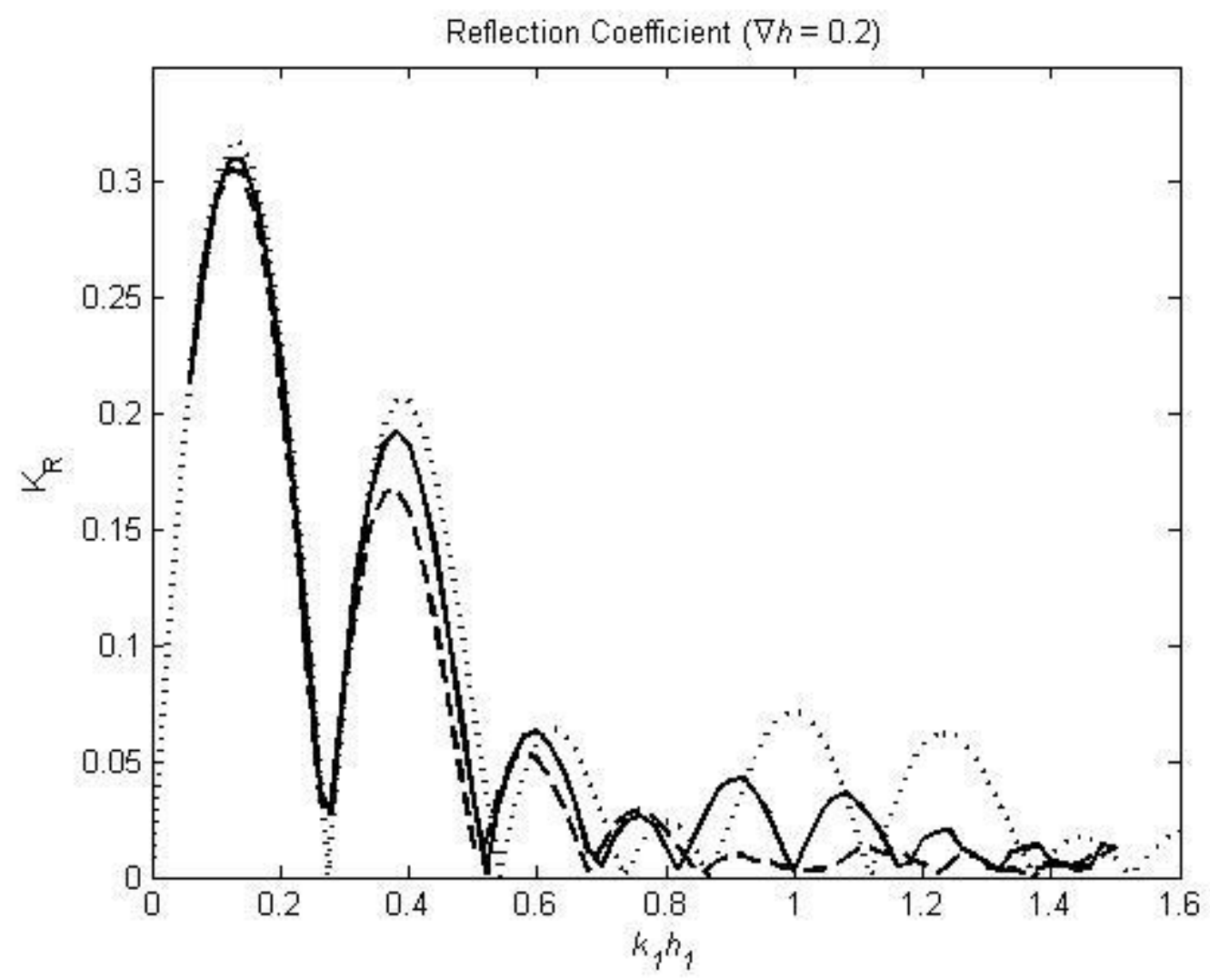

Fig. 2 


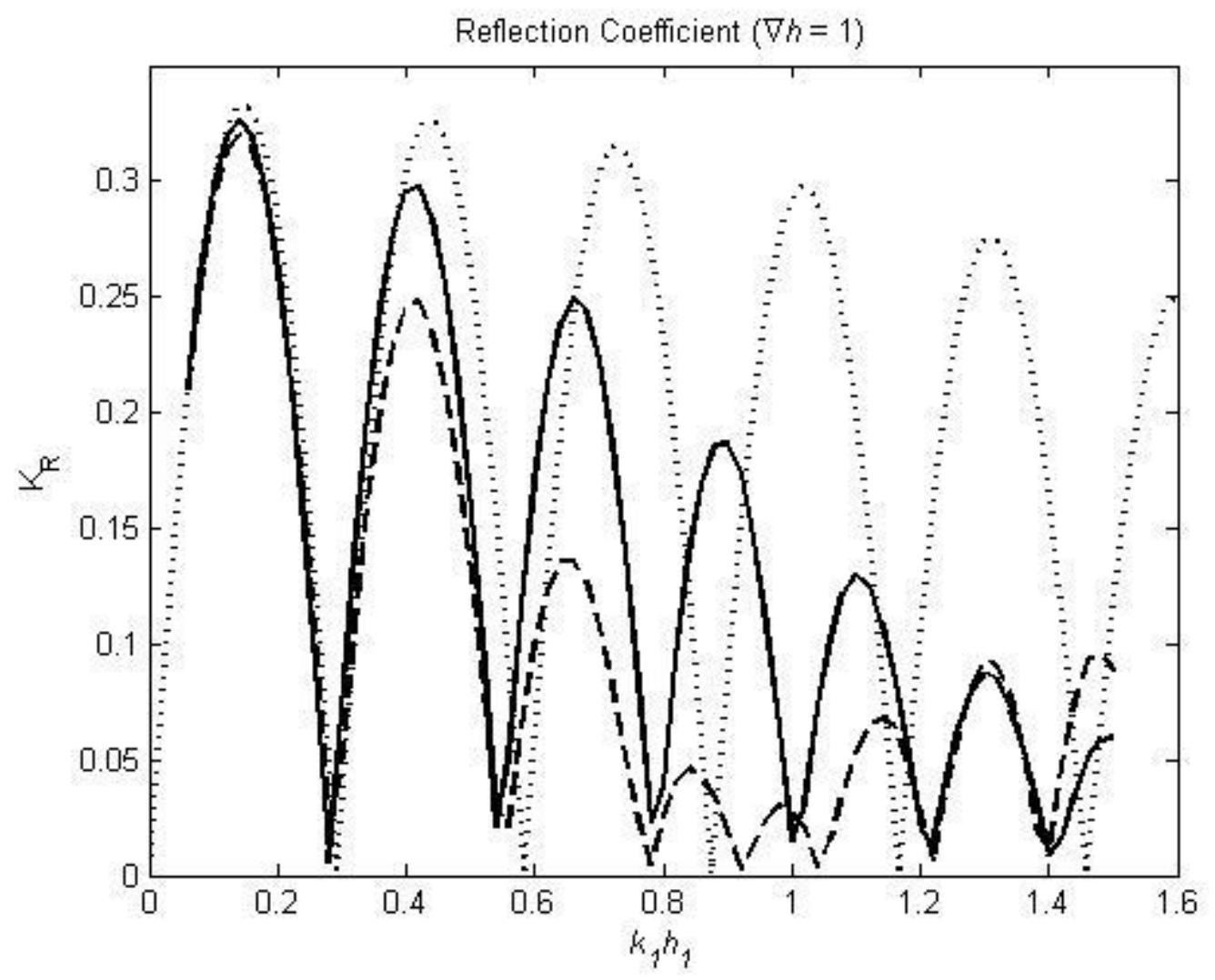

Fig. 3 


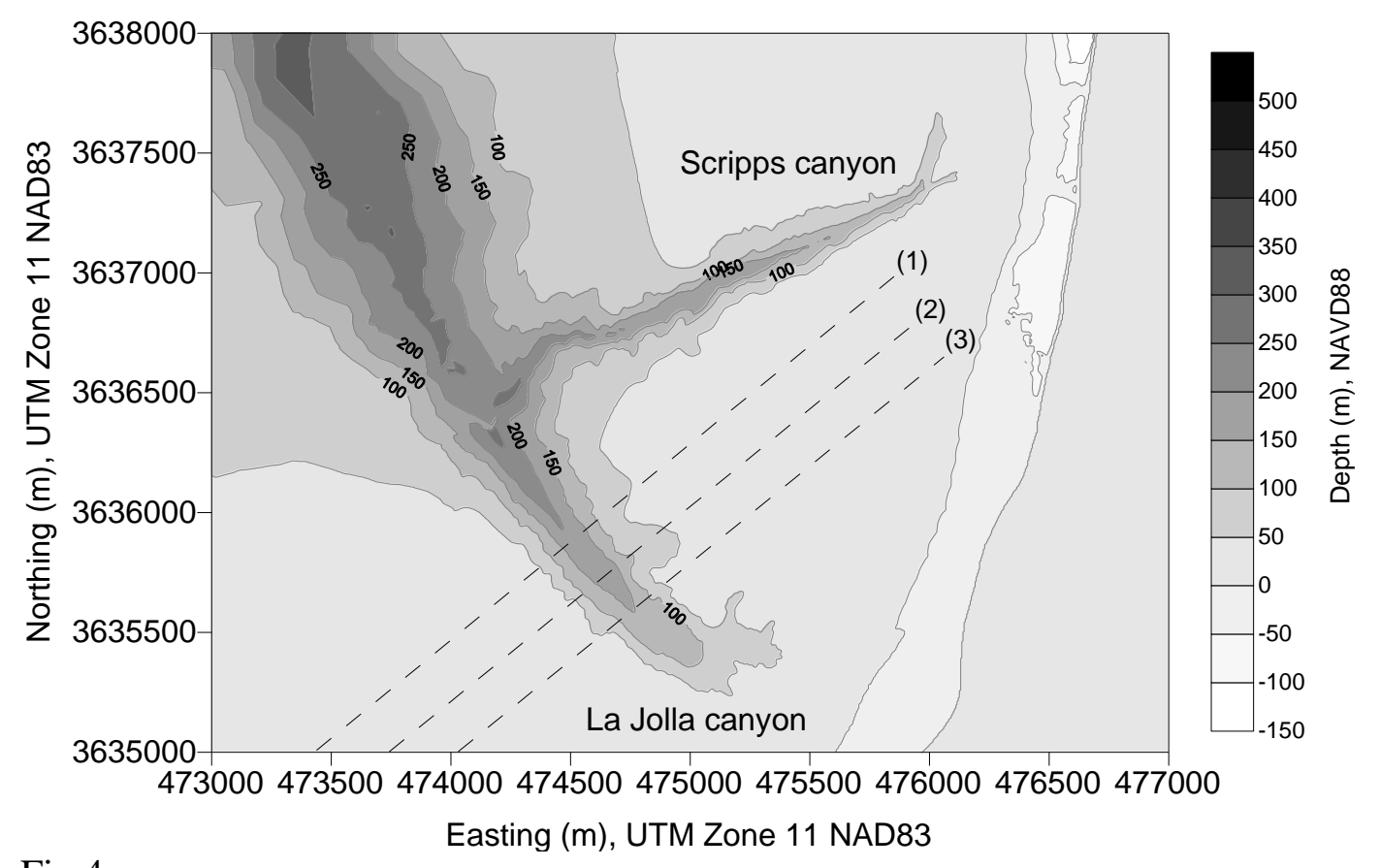

Fig 4: 


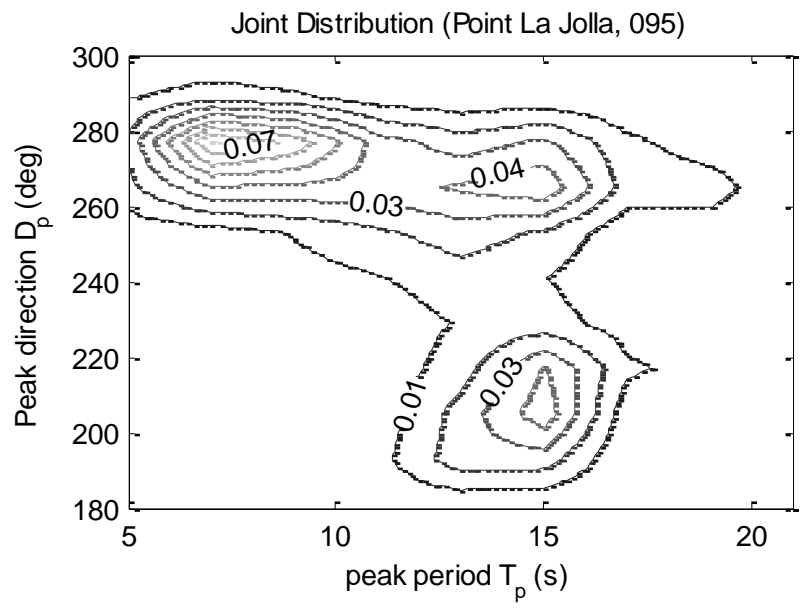

Fig 5: 


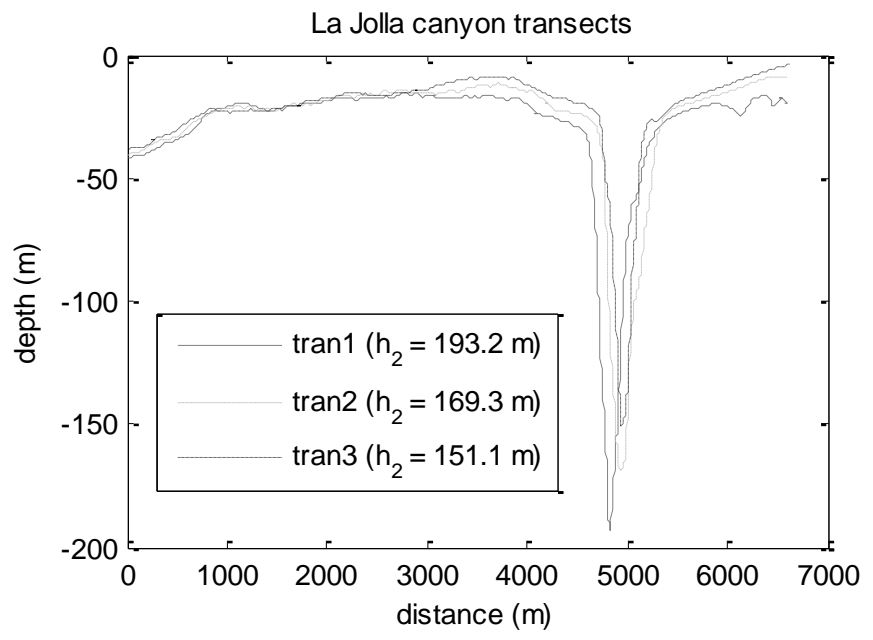

Fig 6: 


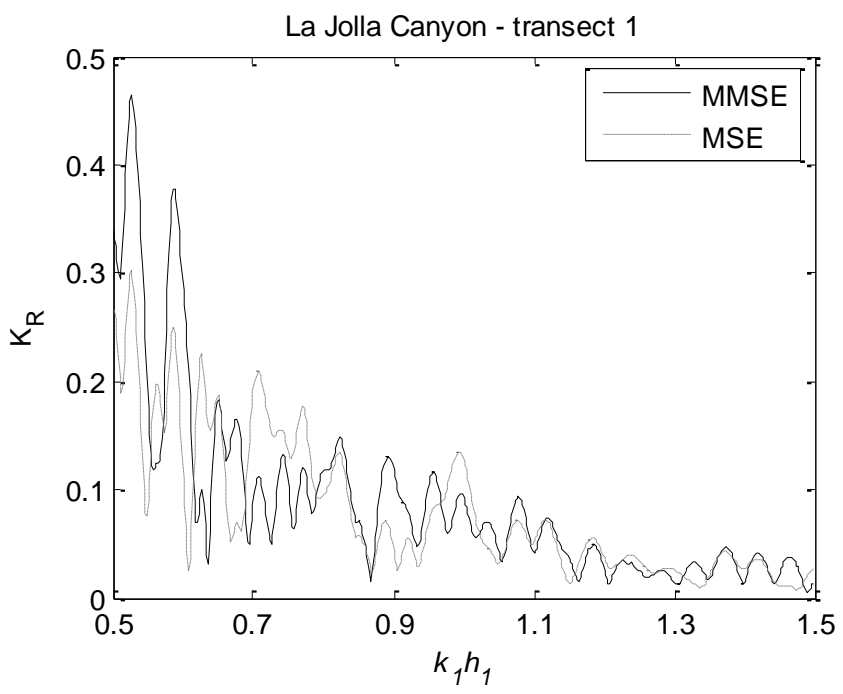

Fig 7: 


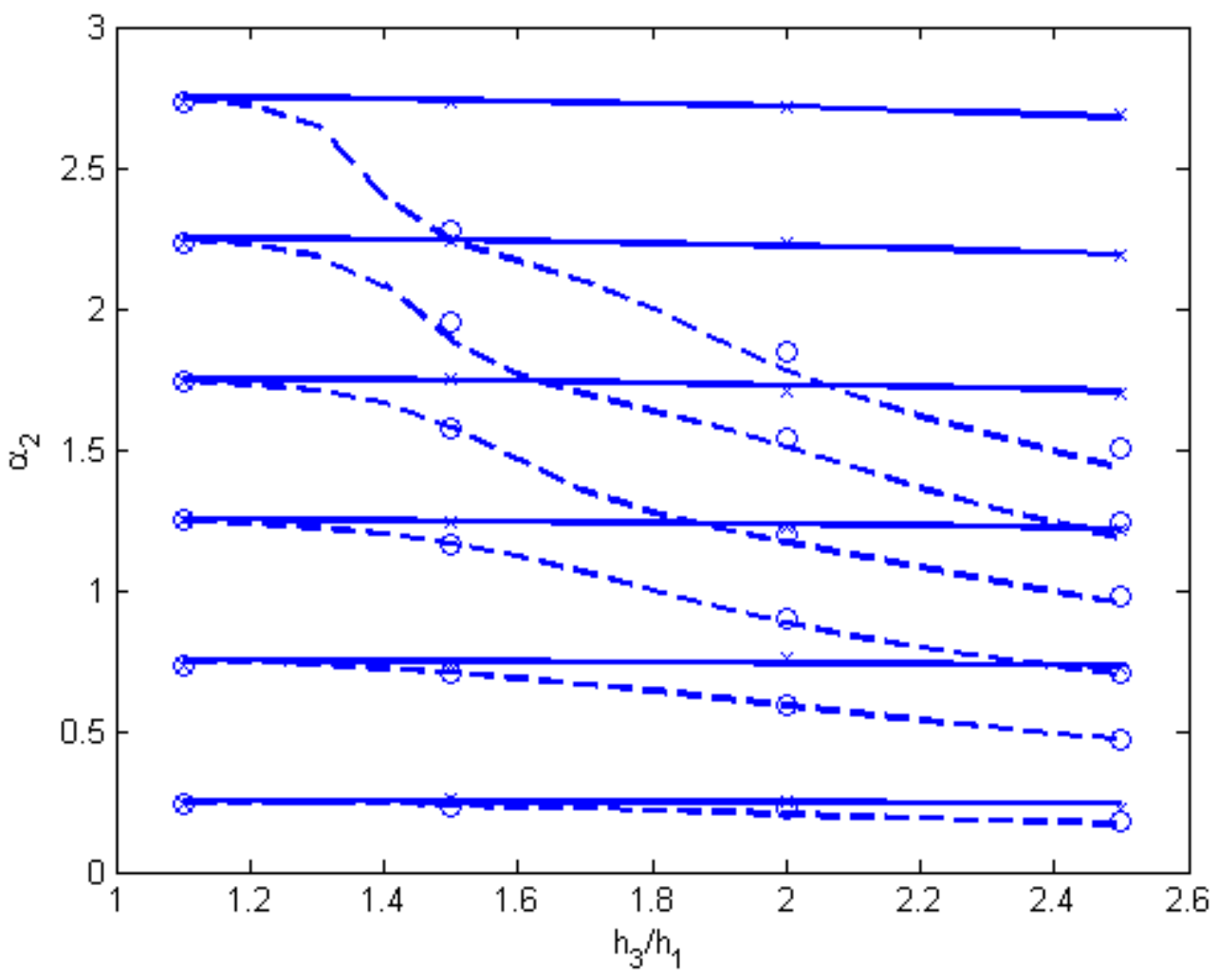

Fig 8: 

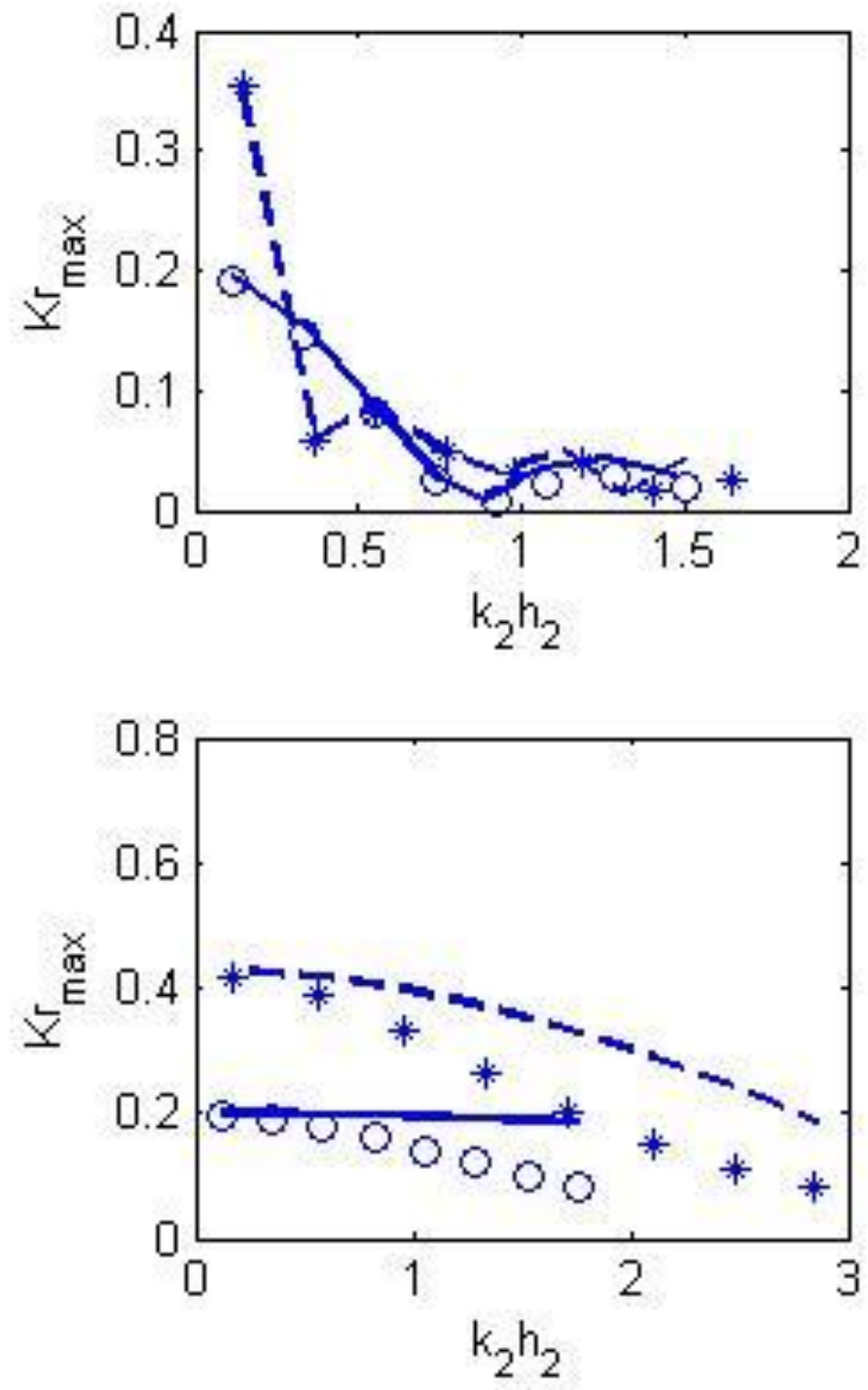

Figures 9a and 9b: 
Fig. 1. Model domain for idealized trench with sloping walls; wall slope of $\nabla h=\infty$ (solid), $\nabla h=1$ (dotted), $\nabla h=0.2$ (dashed).

Fig. 2. Reflection vs. relative water depth for $\bar{a} / h_{1}=15, \nabla h=0.2, \Delta x=0.1 \mathrm{~m}$; calculated using MMSE (solid), MSE (dashed), and long wave solution (dotted).

Fig. 3. Reflection vs. relative water depth for $\bar{a} / h_{l}=15, \nabla h=1, \Delta x=0.1 \mathrm{~m}$; calculated using MMSE (solid), MSE (dashed), and long wave solution (dotted).

Fig. 4. Bathymetric contours in the area of Scripps and La Jolla Canyons (data compiled by CDIP, Scripps Institution of Oceanography).

Fig. 5. Joint distribution of peak wave direction and period from CDIP buoy 095 (Point La Jolla, $32.848^{\circ} \mathrm{N}-117.353^{\circ} \mathrm{W}$ ), contour interval is 0.01 .

Fig. 6. Depth transects 1-3 of La Jolla Canyon; meters from MSL

Fig. 7. Reflection vs. relative water depth for transect 1 for incident wave periods $T=11.1 \sim$ $27.0 \mathrm{~s}\left(h_{1}=41.8 \mathrm{~m} ; h_{2}=193.2 \mathrm{~m}\right)$.

Fig. 8. Effect of trench sidewall slope on $\alpha_{2} ; \bar{a} / h_{1}=20$, slope 1:1 (x), slope 1:10 (o) MMSE solution; LL solution slope 1:1 (solid), slope 1:10 (dashed)

Fig. 9. Peak reflection coefficients vs. relative water depth in the trench, a) slope $=1: 10$, b) slope 1:1. For both (a) and (b) h2/h1=1.5 (o) MMSE, (solid) LL; h2/h1=2.5 (*) MMSE, (dashed) LL. 